\title{
Compressive Strength, Surface Roughness, Fluoride Release and Recharge of Four New Fluoride-releasing Fissure Sealants
}

\author{
Sule KAVALOGLU CILDIR and Nuket SANDALLI \\ Department of Pedodontics, Faculty of Dentistry, Yeditepe University, Istanbul, Turkey \\ Corresponding author, Sule KAVALOGLU CILDIR; E-mail: sulecildir@gmail.com, sulecildir@yahoo.com.tr
}

Received October 20, 2006 /Accepted December 30, 2006

\begin{abstract}
The aim of this study was to investigate the compressive strength and surface roughness of two glass ionomer cements and two resin-based fissure sealants before and after fluoride release and recharge. Twenty-one specimens were prepared and divided into three groups for each material. First group was loaded in compression until failure. Fluoride released was measured from the remaining specimens, and then the second group of seven specimens was loaded at $28^{\text {th }}$ day. The remaining seven specimens were exposed to $0.05 \% \mathrm{NaF}$ solution and $1.23 \% \mathrm{APF}$ gel. Fluoride amount was measured, and the last group was loaded at $70^{\text {th }}$ day. Surface roughness measurement of five more disk-shaped specimens from each material was also carried out. After exposure to APF gel, all materials were recharged. At the end of experimental period, it was found that surface roughness increased, whereas compressive strength decreased, over time. In conclusion, fluoride-releasing fissure sealants could act as show, rechargeable fluoride release systems. However, if a fissure sealant exhibited high fluoride release, it had inferior mechanical properties.
\end{abstract}

Keywords: Fissure sealants, Fluoride release, Physical properties

\section{INTRODUCTION}

Caries in pits and fissures accounts for a major part of dental caries experience in children and adolescents. In general, the highest risk of developing occlusal caries occurs within the first three years after eruption of molars. However, presently, in the age group of 13 to 15 years, occlusal restorations account for more than 80 per cent of the total number of dental restorations ${ }^{1-3)}$. In light of the rampancy of dental caries, various caries prevention materials and techniques have been advocated for susceptible pit and fissure areas in posterior teeth especially for child patients and high-risk caries patients $^{2,4)}$. In connection with these caries prevention and control programs, sealants are used to penetrate the pits and fissures and thereby seal these areas against oral bacteria and food debris ${ }^{1,2,4,5}$.

In caries prevention, the preventive effect of fluoride on caries has been unequivocally established. Porous enamel and softened dentine can be remineralized in the presence of fluoride ${ }^{6,7}$. However, to provide a low but effective quantity of fluoride over a prolonged period, it would have to be a slow and rechargeable fluoride release system from dental materials ${ }^{8-10)}$. The amount of fluoride adequate and necessary for curing carious lesions and for other anticariogenic effects is not well documented. However, it may be assumed that fluoride content should be as high as possible, but without adverse effects on the physical and mechanical properties of the dental material. Further, there should be an initial burst effect to stop caries and induce remineralization in addition to the long-term release ${ }^{5-7,9)}$. However, the amount of fluoride released differs significantly among different materials, suggesting that many factors - such as dental material formulation - influence the amount of fluoride released. At this juncture, it is worth mentioning that fluoride-releasing sealants - apart from their role in pit and fissure caries prevention - can also help to maintain a low level of fluoride in saliva $a^{50}$.

Fluoride is cleared rather rapidly from the oral fluid. This means that fluoride level is back to its baseline value within a relatively short period of time. To circumvent this phenomenon, topical fluoride agents or fluoride-containing mouthwashes and toothpastes are used to partially regenerate or recharge the fluoride-releasing capability in the oral fluid $^{11-133}$. However, the recharge capability varies widely among different types of fluoride-releasing fissure sealants; in particular, glass ionomers are capable of absorbing fluoride from external sources. Besides, sodium fluoride is incorporated into the fillers of some sealants to act as a fluoride reservoir from which the added fluoride is gradually released into the oral cavity ${ }^{2,7,10,13,14)}$.

With respect to fissure sealants, significant advancements in chemistry and applications of dental materials have contributed to their success ${ }^{1,15,16)}$. The components of sealants are similar to those of composite resin restorative materials. They provide reasonable flowability due to their low viscosity, good wettability, and improved physical properties. However, a major disadvantage of composite resinbased materials is their shrinkage at polymerization, causing gap formation - thereby leading to bacterial penetration and then restoration failure ${ }^{4,16,17)}$. Against this background, glass ionomers have been suggested as an alternative material for sealants. The main 
clinical advantage of this material is its ability to bond chemically to dentin and enamel without the use of acid-etch technique, which increases the vulnerability to moisture absorption ${ }^{14,17,18}$.

It is reported that the fluoride release level of glass ionomers is higher than that of resin-based fissure sealants. As such, glass ionomer cements can probably be recommended as a "fluoride depot" rather than as a conventional mechanical barrier occluding susceptible fissures. However, clinical studies have found retention of glass ionomers to be significantly poorer than that of resins. Moreover, it is reported that the mechanical properties of glass ionomer cements are inferior to those of resin-based fissure sealants ${ }^{15,17-20)}$. Nonetheless, the final choice between resin-based and glass ionomer fissure sealants should be based on adequacy of moisture control. Since resins are the most durable, they should generally be the preferred choice. On the other hand, glass ionomer fissure sealants are recommended for erupting teeth or where co-operation is insufficient to place a conventional resin sealant ${ }^{14,17,18}$.

Presently, the use of fissure sealants with increased biocompatibility, enhanced esthetic appeal, and also improved mechanical properties are still being discussed and studied. Compressive strength is an important property in restorative materials, particularly in the process of mastication. This is because most forces of mastication are compressive. Moreover, when comparing materials that are brittle and generally weak in tension (and hence not employed where tensile forces predominate), compressive strength is a useful benchmark ${ }^{21-24}$.

Another well-documented factor that contributes to the success of dental restorations is a smooth surface $^{25-27)}$. Bollen et al. reported a mean roughness of $0.2 \mu \mathrm{m}$ as the critical threshold value for bacterial retention ${ }^{25}$. Surface roughness exceeding $0.2 \mu \mathrm{m}$ was found to result in a simultaneous increase in plaque accumulation, thereby increasing the risk of caries development and periodontal inflammation ${ }^{25)}$.

Similarly, it has been reported that materials with high fluoride release have lower mechanical properties than materials with low fluoride release ${ }^{24)}$.
In other words, the clinical success of a dental material is also influenced by its fluoride release behavior, since the latter may have an adverse effect on mechanical properties. However, reports pertaining to the physical and mechanical properties of sealants have been scarce because sample preparation with such low-viscosity materials is difficult.

The aims of this study, therefore, were to determine whether there was any association between mechanical properties and fluoride release, as well as between fluoride release and fluoride recharge capabilities, of two glass ionomer cements formulated for fissure sealing and two resin-based light-cured fissure sealants.

\section{MATERIALS AND METHODS}

\section{Specimen preparation}

Two different types of glass ionomer cements (GIC) formulated for fissure sealing (Fuji VII, GC Belgium; Ketac Molar, 3M ESPE USA) and two different types of resin-based light-cured fissure sealants (Clinpro, 3M ESPE USA; Embrace, Pulpdent, USA) were selected for this study. Table 1 lists the materials selected for this investigation and their manufacturers.

A hundred and four disk-shaped specimens were prepared by using metallic molds by one operator (CILDIR SK). Twenty-one specimens (4 $\mathrm{mm}$ diameter and $6 \mathrm{~mm}$ height) from each material were prepared for compressive strength experiment, and five specimens $(8 \mathrm{~mm}$ diameter and $2 \mathrm{~mm}$ height) from each material were prepared for surface roughness experiment. Each material was cured or mixed according to the manufacturer's instructions and then placed in the metallic mold, covered with polyethylene sheets, and pressed between two glass sheets to the thickness of the mold. Specimens were stored in their molds for one hour before having their thickness and diameter measured. Then, each specimen was transferred to plastic test tubes containing $3 \mathrm{ml}$ of deionized water. Both samples and containers were incubated at $37^{\circ} \mathrm{C}$ during the entire experimental period.

Table 1 Fissure sealants selected for this investigation and their manufacturers

\begin{tabular}{ccc}
\hline Material & Type & Manufacturer \\
\hline Clinpro & Resin-based light-cured fissure sealant & 3 M ESPE, USA \\
Embrace & Resin-based light-cured fissure sealant & Pulpdent, USA \\
Fuji VII & Glass ionomer cement formulated for & GC, Belgium \\
Ketac Molar & Glass ionomer cement formulated for & fissure sealant
\end{tabular}




\section{Fluoride ion measurement}

Fluoride release was analyzed using a fluoride ion selective electrode (9609 BN, Orion Research) connected to an ion analyzer (Orion 720A+). The fluoride electrode was maintained according to manufacturer's instructions and calibrated daily with standard solutions. The required concentrations of standard solutions, $0.1 \mathrm{ppm}, 1 \mathrm{ppm}, 10 \mathrm{ppm}$, and 100 ppm, were prepared from a 100-ppm F stock solution (Orion 94-09-07). After every 10 measurements, the electrode was recalibrated with the standard solutions. All concentrations were given as parts per million (ppm).

To prevent fluoride build-up that might interfere with weekly measurements, the sample solutions were changed 24 hours before fluoride analysis. After caps were placed on the tubes, the samples were incubated for 24 hours at $37^{\circ} \mathrm{C}$. Following 24 hours' incubation, each sample was transferred to a new tube containing $3 \mathrm{ml}$ of fresh, distilled deionized water. Each specimen was clasped with a pair of clean metal forceps and rinsed with $1 \mathrm{ml}$ of distilled deionized water over the original holding tube, thus collecting the rinse water in that tube. After which, the specimen was dried for one minute on absorbent paper, placed in a new tube containing $3 \mathrm{ml}$ of fresh, distilled deionized water, and incubated at $37^{\circ} \mathrm{C}$.

Fluoride ion concentration for each incubation period was determined by adding $0.4 \mathrm{ml}$ of Total Ionic Strength Adjustment Buffer (TISAB III, No. 940911, Orion) to each test tube. The TISAB buffer was added to provide a constant background of ionic strength, thereby ionizing the fluoride present in the solution and adjusting the $\mathrm{pH}$ of the solution. Fluoride sample containing TISAB buffer was stirred with a magnetic stirrer for five seconds before the fluoride electrode was positioned immediately in the sample for measurement. The electrode membrane was rinsed well with deionized water and blotted dry between tests.

\section{Compressive strength measurement}

Twenty-one specimens were randomly divided into three groups. First group was loaded in compression until failure, and the initial compressive strength values were determined by using an Instron 3345 mechanical testing machine with a crosshead speed of $1 \mathrm{~mm} / \mathrm{min}$. Fluoride released from the remaining specimens was measured at $1^{\text {st }}, 2^{\text {nd }}, 3^{\text {rd }}, 4^{\text {th }}, 7^{\text {th }}, 14^{\text {th }}$, $21^{\text {st }}$, and $28^{\text {th }}$ days. At $28^{\text {th }}$ day, the second group of seven specimens from each material was loaded in compression and the compressive strength values after one month of fluoride release were obtained.

The remaining seven specimens of each material were exposed to $0.05 \%$ sodium fluoride $(\mathrm{NaF})$ solution at $29^{\text {th }}$ day. Exposure to $0.05 \% \mathrm{NaF}$ was applied once a week on the $29^{\text {th }}$ and $35^{\text {th }}$ days at 10:00 am. At $42^{\text {nd }}$ day, the same specimens were exposed to $1.23 \%$ Acidulated Phosphate Fluoride (APF) gel at 10:00 am. Specimens were rinsed with $2 \mathrm{ml}$ of deionized water for one minute, dried for 30 seconds on absorbent paper, placed in $3 \mathrm{ml}$ of fresh, distilled deionized water, and incubated as before. After refluoridation, fluoride ion measurement of the recharged specimens were measured at $30^{\text {th }}, 31^{\text {st }}, 32^{\text {nd }}, 35^{\text {th }}, 42^{\text {nd }}, 43^{\text {rd }}$, $44^{\text {th }}, 45^{\text {th }}, 49^{\text {th }}, 56^{\text {th }}, 63^{\text {rd }}$, and $70^{\text {th }}$ days using the same method. At $70^{\text {th }}$ day, the last group was also loaded in compression and compressive strength values after refluoridation were obtained.

\section{Surface roughness measurement}

Five disk-shaped specimens from each material were prepared for surface roughness measurement. Fluoride ion measurement and refluoridation were performed on these specimens on the same days, as mentioned above. After storage for 24 hours at $37^{\circ} \mathrm{C}$, the specimens were polished with 2500-grit $\mathrm{SiC}$ paper. Surface roughness of the specimens was determined using a surface profilometer (Perthometer M1, Mahr), with a tracing length set at $1.5 \mathrm{~mm}$ and a cut-off value at $0.25 \mathrm{~mm}$, on $1^{\text {st }}, 28^{\text {th }}$, and $70^{\text {th }}$ days. Each sample was rotated $120^{\circ}$ to record three readings per surface, and the average value of these three readings was recorded for each specimen. The instrument provided the average surface roughness, $\mathrm{Ra}$, per tracing in microns. $\mathrm{Ra}$ is the arithmetic average height of roughness irregularities measured from a mean line within the sampling length.

\section{Statistical analysis}

Statistical analysis was performed with a GraphPad Prisma V3 program. Data were analyzed by Friedman, Kruskal-Wallis, Dunn's multiple comparison, and Pearson's correlation tests. Comparisons were considered to be significant at $\mathrm{p}<0.05$.

\section{RESULTS}

Before refluoridation, all materials released fluoride

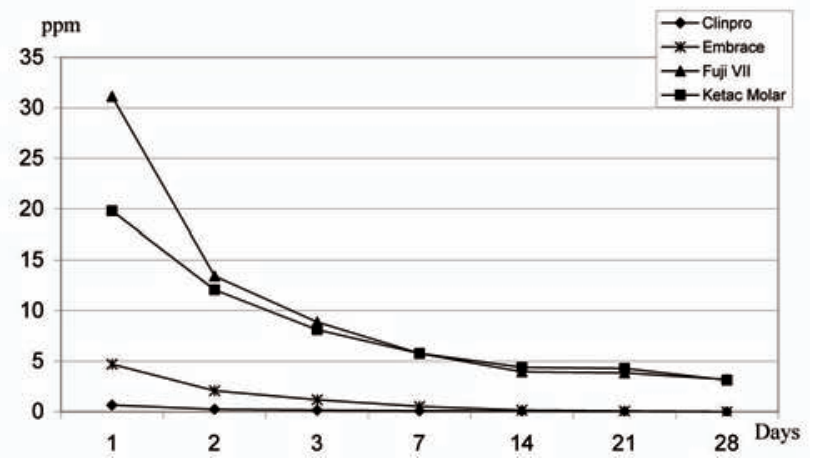

Fig. 1 Mean levels of fluoride release of each material before refluoridation. 


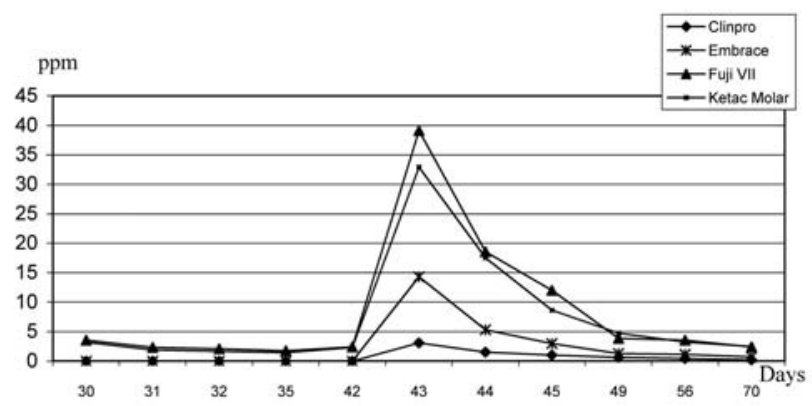

Fig. 2 Mean levels of fluoride release of each material after refluoridation.

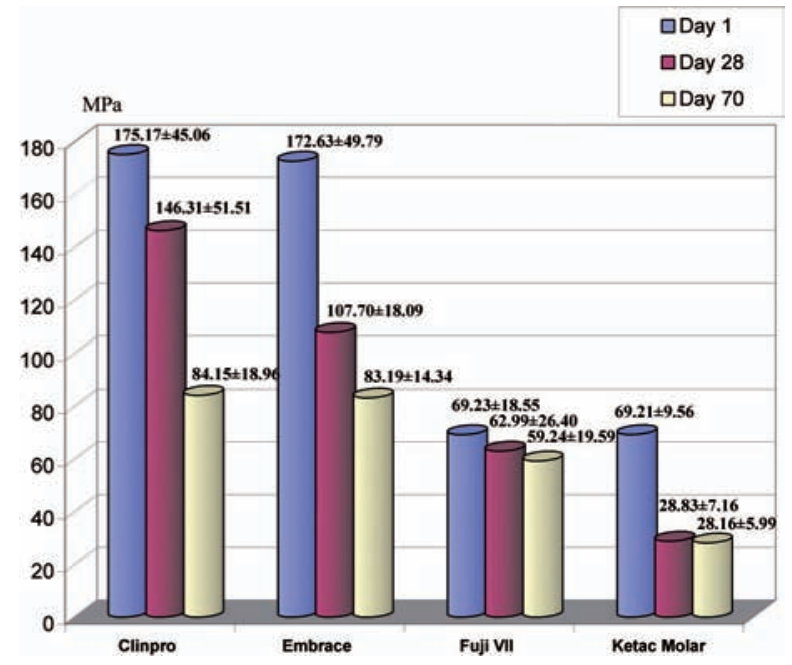

Fig. 3 Mean values and standard deviations of compressive strength of each material.

at the stipulated time intervals. Highest amount of fluoride was obtained during the first 24 hours, but sharply dropped on the second day. It then remained at a low and constant level after approximately one week (Fig. 1). There were statistically significant differences between the amounts of fluoride released from resin-based fissure sealants and those from GICs formulated as fissure sealants $(p<0.0001)$. Throughout the study, Fuji VII released significantly more fluoride than the other materials $(p<0.0001)$. Ketac Molar was next, and Clinpro ranked the lowest. At 28th day, no fluoride release was detected from Clinpro and Embrace.

Comparisons among the recharged test specimens, especially on $30^{\text {th }}, 42^{\text {nd }}, 43^{\text {rd }}$, and $70^{\text {th }}$ days, were significantly different. After exposure to $0.05 \% \mathrm{NaF}$ solution, there was no increase in fluoride release amount from Clinpro and Embrace, while Fuji VII and Ketac Molar increased insignificantly. After exposure to $1.23 \% \mathrm{APF}$, the initial fluoride ion release increased significantly for all materials $(p<0.001)$. The highest rate was achieved by all materials on the first day of refluoridation, but dropped sharply to a constant, low level (Fig. 2). After refluoridation, Fuji VII and Ketac Molar released

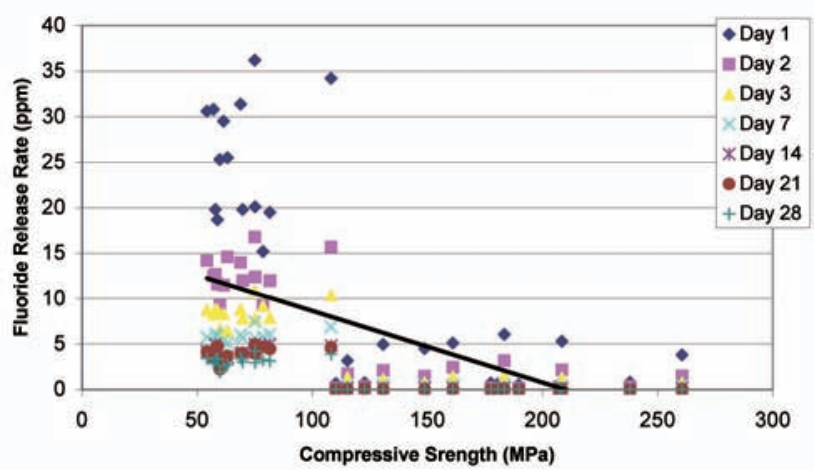

Fig. 4 Correlation between compressive strength and fluoride release.

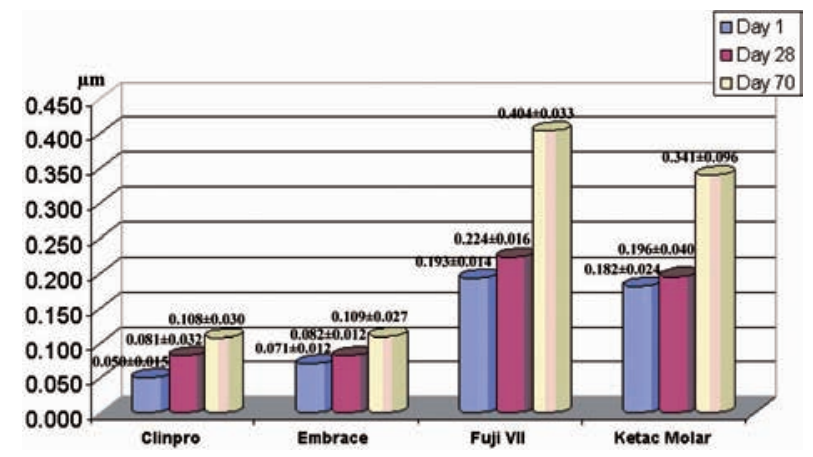

Fig. 5 Mean values and standard deviations of surface roughness of each material.

significantly more fluoride than Embrace and Clinpro at all measurement days $(\mathrm{p}<0.05)$.

Figure 3 shows the mean levels of compressive strength. Sealants with the same letter had no significant differences. Compressive strength values for Clinpro and Embrace were significantly higher than Fuji VII and Ketac Molar at all measurement days $(p<0.0001)$. Comparisons between the measurement days within each material were significantly different, except for Fuji VII $(p<0.001)$. A negative correlation between compressive strength and fluoride release was found (Fig. 4) $(r=-0.736, p<0.0001)$.

Figure 5 shows the mean levels of surface roughness. Surface roughness values of all materials were observed to gradually increase toward the $70^{\text {th }}$ day. Sealants with the same letter had no significant differences $(p>0.05)$. Further, highest surface roughness value was found in Fuji VII at all measurement days, and the lowest in Clinpro. For all materials, there were statistically significant differences in surface roughness value between the initial and $70^{\text {th }}$ days $(\mathrm{p}<0.01$ and $\mathrm{p}<0.05$, respectively). 


\section{DISCUSSION}

For caries prevention programs in pediatric dentistry, fluoride-releasing fissure sealants are used as a means to provide a continuous, low level of fluoride in the oral environment ${ }^{1,2,5)}$. Jensen et al. ${ }^{28)}$ and Hicks et $a 5^{5.29)}$ reported that compared to non-fluoridecontaining fissure sealants, fluoride-containing fissure sealants significantly reduced the amount of demineralization in adjacent enamel. In general, the pattern of fluoride release by glass ionomers is in agreement among the findings of many research$\operatorname{ers}^{7,14,20)}$. However, less research was done on the fluoride release behavior of resin-based fissure sealants, ${ }^{5,23)}$. In the present study, all the evaluated fissure sealant materials released fluoride. However, throughout the study, glass ionomer fissure sealants released more fluoride than resin-based fissure sealants. This difference in fluoride release behavior arose from their differences in chemical composition.

The amount of fluoride released among the selected materials differed significantly, suggesting that many factors - such as dental material formulation and amount of fluoride incorporated in the material-wielded an effect on the amount of fluoride released ${ }^{7,10,13,14,30)}$. When compared with the GICs, the amount of fluoride released from the resinbased fissure sealants was minimal ${ }^{7,13,18,19}$.

Currently, fluoride-containing fissure sealants are being marketed, and both in vivo and in vitro studies of fluoride release have been reported. In both studies, fluoride release was rapid and the major fluoride release occurred within the first two days ${ }^{5,14,19,28,31)}$. The problem with the release of fluoride in all these studies was that there was a "burst effect" in which great amounts of fluoride were released during the first 24 hours. Thereafter, the amount of fluoride released dropped sharply on the second day and decreased slowly during the last days. In particular after the second week, the fluoride release rate slowed down to almost no differences in fluoride elution between days ${ }^{10,12,30,32}$. As for this study, the findings were similar. There were statistically significant differences between the initial fluoride release rates of resin-based fissure sealants versus those of GICs. Highest amount of fluoride was released from Fuji VII (31.143 \pm 3.47$)$, while Clinpro ranked the lowest $(0.665 \pm 0.086)$. This observation was supported by previous studies ${ }^{7,10,12,30)}$. From a clinical point of view, these results implied that fluoride-releasing fissure sealants could act as intraoral devices for controlled, slow release of fluoride. Expectedly then, an increase in fluoride concentration in saliva and in adjacent dental hard tissues would be of some benefit to sites at risk of recurrent caries as well as in preventing further demineralization ${ }^{5,6,1933)}$.

Under laboratory conditions, most of the measurements have been made in distilled water and not saliva. In other words, fluoride release occurs in one direction only, from the sealant specimen into water. In the mouth, it is probable that some fluoride release is available from the oral fluid for ionic substitution of the mineral phase of enamel. Moreover, release of fluoride from fluoride materials into artificial human saliva has been shown to be significantly less than into water ${ }^{14,31,3,2,34)}$. However, in a report by El-Mallakh and Sarkar ${ }^{34}$, it was pointed out that the presence of plaque or pellicle which may influence the diffusion of fluoride and fluoride levels - was not taken into account. Further, although fluoride release in artificial saliva more closely simulates an in vivo situation, the organic components in artificial saliva might interfere with the sensitivity of the lanthanum fluoride (LaF) membrane of $\mathrm{F}$ electrode ${ }^{34)}$. Therefore, in this study, deionized water was the preferred medium, just as in many other studies ${ }^{7,1,1,12,13,30}$.

It has been reported that in the oral environment, fluoride-releasing fissure sealants recharge their fluoride content when exposed to fluoridated products such as fluoride gel, mouthwash, or toothpaste $^{7,10,13,27)}$. It has been found that a linear correlation exists between fluoride release and recharge capabilities. In other words, a material with higher initial fluoride release also has a higher fluoride recharge capability ${ }^{22,24)}$. Therefore, for fluoridereleasing fissure sealants, their ability to absorb fluoride from topical agents and subsequently release it serves as an excellent delivery system for fluoride intraorally ${ }^{7,29,35)}$. In the present study, the total amount of fluoride released was significantly higher after exposure to a $1.23 \%$ APF gel than after exposure to $0.05 \% \mathrm{NaF}$ solution. For resin-based fissure sealants, no extra fluoride was released during days 30 to 42 after exposure to $0.05 \% \mathrm{NaF}$, while significant increase was observed for glass ionomer fissure sealants. However, after exposure to $1.23 \%$ APF, fluoride continued to be eluted from all groups; especially for glass ionomers, fluoride release continued until day 70 . These results thus supported the suggestion that the amount of fluoride released after exposure was dependent on the concentration of fluoride solution ${ }^{7,10,12,13)}$.

In the present study, the most important finding was that fissure sealants could be recharged by $1.23 \%$ APF gel. Then, for a long period of time after recharging, a substantial and constant level of fluoride could be maintained in their surrounding environment. In addition, this finding illustrated that a subsequent, follow-on release was not merely a result of wash-out of fluoride ions adsorbed to the disk surface. Most probably, some fluoride had diffused into the material matrix, increasing its fluoride reservoir, and from which fluoride was released 
slowly for a prolonged period ${ }^{7,10,13,35)}$.

Gradual fluoride release by a diffusion process is preferred over the dissolution of material. In this manner, fluoride release is less likely to result in deterioration of the mechanical properties of the material. In the process of mastication, surface roughness and compressive strength are very important mechanical properties of a restorative material. As such, compressive strength test is selected by the International Standards Organization as a test procedure for water-based cements used in dentistry ${ }^{36)}$. ISO compressive strength test specimen dimensions were thus employed in this study.

In the present study, the compressive strength values of all fissure sealants gradually decreased over time, and the decrease was significantly higher in glass ionomer fissure sealants both before and after prophylaxis treatment. It has been reported that a negative correlation exists between fluoride release and compressive strength of glass ionomer and resinbased fissure sealants ${ }^{22-24)}$. Results of the present study agreed with the published literature ${ }^{22-24)}$, whereby it was shown that materials with high fluoride release had lower compressive strengths.

Studies have suggested that $0.2 \mu \mathrm{m}$ was the threshold surface roughness value for bacterial retention. Surface roughness exceeding this threshold value would result in a simultaneous increase in plaque accumulation, thereby increasing the risk of both caries development and periodontal inflammation $^{25,37}$. In this study, the resin-based materials exhibited a statistically smoother surface than the glass ionomers - an observation in agreement with those of similar studies ${ }^{27,37,38)}$. Further, there were no significant differences in surface roughness among the resin-based fissure sealants and among the glass ionomer fissure sealants in our study.

Restorative materials were found to exhibit a significant increase in surface roughness following simulated home-care or prophylaxis treatment. Further, the effect of prophylaxis treatment was found to be material-dependent $t^{25,26,37,38)}$. As for the present study, all fissure sealants demonstrated an increase in surface roughness following prophylaxis treatment. However, glass ionomer fissure sealants yielded significantly higher roughness than the resinbased fissure sealants. Surface roughness increased up to $0.4 \mu \mathrm{m}$ for Fuji VII and $0.3 \mu \mathrm{m}$ for Ketac Molar after APF gel application. This increase in roughness was statistically significant. It should also be noted that the surface roughness values of glass ionomer fissure sealants exceeded the critical threshold value for bacterial retention, a finding likewise supported by previous studies ${ }^{27,39,40)}$.

Clinpro showed the highest mechanical properties, followed by Embrace. Current fissure sealants with a high fluoride release were found to have lower mechanical properties. Conversely, resin-based fissure sealants - though mechanically stronger released only a small amount of fluoride. Ultimately, the choice between resin-based and glass ionomer fissure sealants should be based on the adequacy of moisture control. Since resin-based fissure sealants are the most durable, they should generally — and logically — be the preferred choice. Nonetheless, glass ionomer fissure sealants should be used in cases where moisture control is difficult, e.g., in erupting or newly erupted teeth. In these cases, glass ionomer fissure sealants are regarded more as temporary fissure sealants or as a fluoride release vehicle, rather than as true, permanent fissure sealants. As for resin-based fissure sealants, their fluoride release characteristic coupled with their good, long-term mechanical properties, auger well for their potential use in clinical situations.

\section{CONCLUSIONS}

From a clinical point of view, results of the present study implied that fluoride-releasing fissure sealants might act as intraoral devices for controlled, slow release of fluoride at sites at risk of recurrent caries. As such, we would thus recommend topical fluoride application to be used in conjunction with these materials as a preventive measure against caries. Further, after prophylaxis treatment, polishing is also recommended to prevent surface roughness.

\section{ACKNOWLEDGEMENTS}

The authors wish to express their sincere thanks to Associate Professor, Dr. Nurhan Guler, for her invaluable technical assistance throughout the preparation of this article.

\section{REFERENCES}

1) Feigal RJ. The use of pit and fissure sealants. Pediatr Dent 2002; 24:415-422.

2) Mertz-Fairhurst EJ, Schuster GS, Fairhurst CW. Arresting caries by sealants: Results of a clinical study. JADA 1986; 112:194-197.

3) Clinical Affairs Committee. Clinical guideline on pediatric restorative dentistry. Am Academy Pediatr Dent 2004; 26:106-114.

4) Craig RG, Powers JM, Wataha JC. Preventive Dental Materials. In: Dental Materials, 8th ed, Mosby, St Louis, 2000, pp.38-45.

5) Hicks MJ, Flaitz CM, Garcia-Godoy F. Fluoridereleasing sealant and caries-like enamel lesion formation in vitro. J Clin Pediatr Dent 2000; 24:215-219.

6) Donly KJ, Gomez C. In vitro demineralizationremineralization of enamel caries at restoration margins utilizing fluoride-releasing composite resin. Quint Int 1994; 25:355-358. 
7) Forsten L. Fluoride release and uptake by glassionomers and related materials and its clinical effect. Biomaterials 1998; 19:503-508.

8) ten Cate JM, van Loveren C. Fluoride mechanisms. Dent Clin North Am 1999; 43:713-742.

9) Arends J, Ruben A, Dijkman AG. Effect of fluoride release from a fluoride containing composite resin on secondary caries: an in vitro study. Quint Int 1990; 21:671-674.

10) Dionysopoulos P, Kotsanos N, Pataridou A. Fluoride release and uptake by four new fluoride releasing restorative materials. J Oral Rehabil 2003; 30:866-872.

11) Hatibovic-Kofman S, Koch G, Ekstrand J. Glass ionomer materials as a rechargeable fluoride-release system. Int J Paediatr Dent 1997; 7:65-73.

12) Cildir SK, Sandalli N. Fluoride release/uptake of glass ionomer cements and polyacid-modified composite resins. J Dent Mater 2005; 24:92-97.

13) Takahashi K, Emilson CG, Birkhed D. Fluoride release in vitro from various glass ionomer cements and resin composites after exposure to $\mathrm{NaF}$ solutions. Dent Mater 1993; 9:350-354.

14) Rock WP, Foulkes EE, Perry H, Smith AJ. A comparison study of fluoride-releasing composite resin and glass ionomer materials used as fissure sealants. J Dent 1996; 24:275-280.

15) Nunn JH, Murray JJ, Smallridge J. British Society of Paediatric Dentistry: a policy document on fissure sealants in paediatric dentistry. Int $\mathrm{J}$ Paediatr Dent 2000; 10:174-177.

16) Geiger SB, Gulayev S, Weiss EI. Improving fissure sealant quality: Mechanical preparation and filling level. J Dent 2000; 28:407-412.

17) Welbury R, Raadal M, Lygidakis NA. EAPD guidelines for the use of pit and fissure sealants. Eur J Paediatr Dent 2004; 5:179-184.

18) Mejare I, Mjor IA. Glass ionomer and resin-based fissure sealants: a clinical study. Scand J Dent Res 1990; 98:345-350.

19) Forss H, Saarni UM, Seppa L. Comparison of glassionomer and resin-based fissure sealants: a 2-year clinical trial. Community Dent Oral Epidemiol 1994; 22:21-24.

20) Boksman L, Gratton DR, McCutcheon E, Plotzke OB, Paed D. Clinical evaluation of a glass ionomer cement as a fissure sealant. Quint Int 1987; 18:707709.

21) Yap AUJ, Pek YS, Cheang P. Physico-mechanical properties of a fast-set highly viscous GIC restorative. J Oral Rehabil 2003; 30:1-8.

22) Yoshida K, Atsuta M. Properties of fluoride-releasing light-activated resin cement. Dent Mater 1999; 15:337341.

23) Cattani-Lorente MA, Dupuis V, Moya F, Payan J, Meyer JM. Comparative study of the physical properties of a polyacid-modified composite resin and a resin-modified glass ionomer cement. Dent Mater 1999; 15:21-32.

24) $\mathrm{Xu} \mathrm{X}$, Burgess JO. Compressive strength, fluoride release and recharge of fluoride-releasing materials. Biomaterials 2003; 24:2451-2461.

25) Bollen CML, Lambrechts P, Quirynen M. Comparison of surface roughness of oral hard materials to the threshold surface roughness for bacterial plaque retention: A review of the literature. Dent Mater 1997; 13:258-269.

26) Yap AU, Wu SS, Chelvan S, Tan ES. Effect of hygiene maintenance procedures on surface roughness of composite restoratives. Oper Dent 2005; 30:99-104.

27) Wu SS, Yap AU, Chelvan S, Tan ES. Effect of prophylaxis regimens on surface roughness of glass ionomer cements. Oper Dent 2005; 30:180-184.

28) Jensen ME, Wefel JS, Triolo PT, Hammesfahr PD. Effects of a fluoride-releasing fissure sealant on artificial enamel caries. Am J Dent 1990; 3:75-78.

29) Hicks J, Garcia-Godoy F, Donly K, Flaitz C. Fluoridereleasing restorative materials and secondary caries. Dent Clinc North Am 2002; 46:247-276.

30) Garcia-Godoy F, Abarzua I, De Goes MF, Chan DCN. Fluoride release from fissure sealants. J Clin Pediatr Dent 1997; 22:45-49.

31) El-Mehdawi SM, Rapp R, Draus FJ, Miklos FL, Zullo TG. Fluoride ion release from ultraviolet light-cured sealants containing sodium fluoride. Pediatr Dent 1985; 7:287-291.

32) Morphis TL, Touma JK, Lygidakis NA. Fluoride pit and fissure sealants: a review. Int $\mathrm{J}$ Paediatr Dent 2000; 10:90-98.

33) Bravo M, Garcia-Anllo I, Baca P, Llorda JC. A 48month survival analysis comparing sealant (Delton) with fluoride varnish (Duraphat) in 6- to 8-year-old children. Community Dent Oral Epidemiol 1997; 25:247-250.

34) El Mallakh BF, Sarkar NK. Fluoride release from glass-ionomer cements in de-ionized water and artificial saliva. Dent Mater 1990; 6:118-122.

35) Koga H, Kameyama A, Matsukubo T, Hirai Y, Takaesu $\mathrm{Y}$. Comparison of short-term in vitro fluoride release and recharge from four different types of pit-andfissure sealants. Bull Tokyo Dent Coll 2004; 45:173179.

36) International Standards Organization. ISO/FDIS 9917-1:2003.

37) Neme AL, Frazier KB, Roeder LB, Debner TL. Effect of prophylactic polishing protocols on the surface roughness of esthetic restorative materials. Oper Dent 2002; 27:50-58.

38) Rios D, Honorio HM, de Araujo PA, Machado MA. Wear and superficial roughness of glass ionomer cements used as sealants, after simulated toothbrushing. Pesqui Odontol Bras 2002; 16:343-348.

39) Turssi CP, de Magalhaes CS, Serra MC. Effect of fluoride gels on micromorphology of resin-modified glass ionomer cements and polyacid-modified resin composites. Quint Int 2001; 32:571-577.

40) Yip HK, To WM, Smales RJ. Effects of artificial saliva and APF gel on the surface roughness of newer glass ionomer cements. Oper Dent 2004; 29:661-668. 